\title{
Experimental study on fracture behaviour of polycrystalline ceramics under shock loading
}

\author{
J. T. Zhou \& G. W. Yao \\ School of Civil Engineering and Architecture, \\ Chongqing Jiaotong University, People's Republic of China
}

\begin{abstract}
Plate impact experiments and impact recovery experiments were performed on $92.93 \mathrm{wt} \%$ alumina ceramics using a 100-mm-diameter compressed-gas gun. Free surface velocity histories were traced by a VISAR velocity interferometer. There is a recompression signal in free surface velocity, which shows evidence of a failure wave in impacted alumina. The failure wave velocities are $1.27 \mathrm{~km} / \mathrm{s}$ and $1.46 \mathrm{~km} / \mathrm{s}$ at stresses of $7.54 \mathrm{GPa}$ and $8.56 \mathrm{GPa}$ respectively. It drops to $0.21 \mathrm{~km} / \mathrm{s}$ after the material released. SEM analysis of recovered samples showed the transit of intergranular microcracks to transgranular microcracks with increasing shock loading. The failure wave in impacted ceramics is a continuous fracture zone which may be associated with the damage accumulation process during the propagation of shock waves.

Keywords: plate impact experiment, alumina ceramics, failure wave, dynamic fracture, SEM.
\end{abstract}

\section{Introduction}

Since failure waves were first observed propagating in glass rods under dynamic compression by Bless et al [1] and in glass plates under high-pressure impulsive loading by Rasorenov et al [2], a series of plate impact experiments, bar impact experiments and impact recovery experiments have been performed on a range of glasses under various impact stresses [3-6]. These experiments show the failure fronts are generated in silicate and filled glasses at a stress near or below their Hugoniot Elastic Limits and propagate from impact surface to interior at velocities in the range of $1.5-2.5 \mathrm{~km} / \mathrm{s}$. The failed glass has lower acoustic impedance and sound speed than the intact material. The failed layer nearly loses 
complete tensile strength, and its shear strength is significantly degraded. The longitudinal stress and transverse strain remain constant cross the failure front, but the transverse stress and longitudinal strain are increasing with time in the region behind the failure front. All these variations of material properties across this front provide experimental evidences for the existence of a failure wave phenomenon for glass under plate normal impact loading.

In recent years, there also have been some wide researches made into other brittle materials. Bourne et al [7] and Zhang et al [8] have extended these studies to the polycrystalline ceramics alumina, silicon carbide and titanium diboride, gabbro and $3 \mathrm{D}-\mathrm{C} / \mathrm{SiC}$ composite materials and have postulated similar impact induced fracture front in these brittle materials. There also been recent discussion of the phenomenon of gradual failure behind the elastic wave in mortar by Grote [9]. In the work presented, we have conducted a matrix of plate impact experiments on alumina monitored by VISAR focused on the rear surface of the sample in seeking to pursue the failure wave in brittle materials other than glass.

\section{Plate impact experiments}

Plate impact experiments on alumina specimens were carried out on the $100 \mathrm{~mm}$ light gas gun. Impact velocities were measured to an accuracy of $1.5 \%$ using three pairs of electric signal pins at different distances away from the impact surface. The copper flyers and targets were circular with different diameters of $94 \mathrm{~mm}$ and $100 \mathrm{~mm}$, with their two cut faces polished in order to ensure smoothness of the impact and measurement area. Free surface velocity histories were traced using VISAR with a fringe constant $101 \mathrm{~m} / \mathrm{s} /$ fringe and a measured response time $1.5 \mathrm{~ns}$. The free surface of target was polished and aluminized with a layer 5000 angstroms in thickness to strengthen the reflection of incident laser (see fig. 1, which shows a schematic of the experimental setup). The impact recovery experiments were also performed to study micro-structures of impacted samples. Cushion rubber was filled in target room to absorb the dynamic energy of flyer and target. The flyer and target will be embedded in rubber.

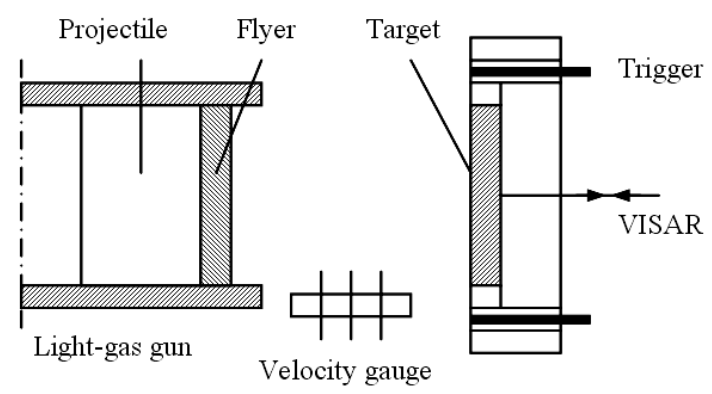

Figure 1: $\quad$ Plate impact experimental schematic with VISAR. 
The alumina samples consist of $92.93 \mathrm{wt} \%$ alumina by weight and a small amount of silicon dioxide, calcium oxide and lanthana analyzed by energy spectrum. The relevant parameters of the specimens are density $3896 \mathrm{~kg} / \mathrm{m}^{3}$, longitudinal sound speed $9.259 \mathrm{~km} / \mathrm{s}$, and a shear wave velocity $5.557 \mathrm{~km} / \mathrm{s}$ respectively. The longitudinal sound speed in copper flyer is $4.60 \mathrm{~km} / \mathrm{s}$ and the thickness of flyers and targets range from $4.0 \mathrm{~mm}$ to $6.1 \mathrm{~mm}$. The acoustic impedance ratio of flyer and target is 1.14 , then long enough duration pulse generates at the impact surface to avoid the unloading wave propagating into targets from flyers. A summary of experimental conditions and results are presented in table 1 .

Table 1: $\quad$ Parameters of plate impact experiments.

\begin{tabular}{|c|c|c|c|c|}
\hline Parameters & $\begin{array}{c}\text { Impact } \\
\text { velocity } \\
(\mathrm{m} / \mathrm{s})\end{array}$ & $\begin{array}{c}\text { Impact } \\
\text { stress } \\
(\mathrm{GPa})\end{array}$ & $\begin{array}{c}\text { Impactor } \\
\text { Thickness } \\
(\mathrm{mm})\end{array}$ & $\begin{array}{c}\text { Target } \\
\text { Thickness } \\
(\mathrm{mm})\end{array}$ \\
\hline Shot 405 & 397.8 & 7.54 & 4.14 & 6.08 \\
\hline Shot 425 & 448.8 & 8.56 & 6.10 & 6.04 \\
\hline
\end{tabular}
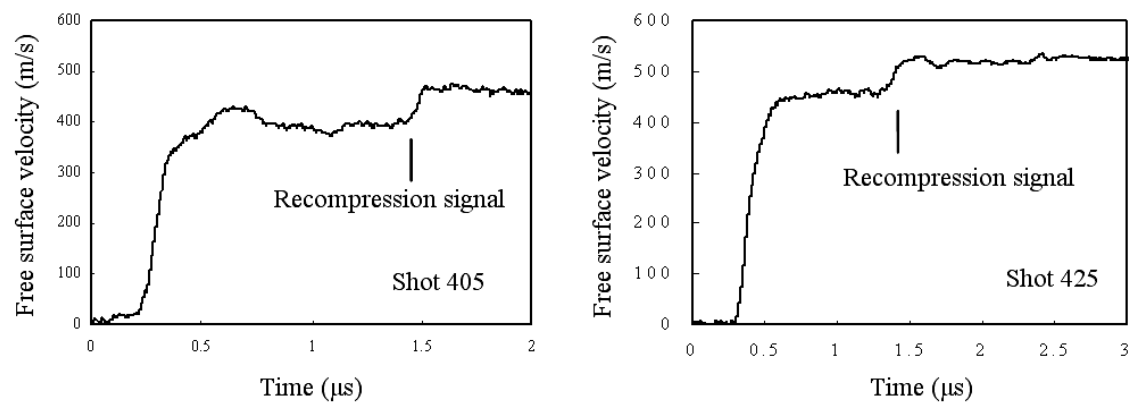

Figure 2: $\quad$ Free surface velocity profiles of shots 405 and 425.

Fig. 2 shows reduced VISAR data by software from the experiments of shots 405 and 425 under shock stresses $7.54 \mathrm{GPa}$ and 8.56GPa. These profiles indicate that the alumina specimens did not spall. The distinct feature of note on the traces is the slight recompression signal pointed on top of the stress wave. This velocity jump behaves beyond the elastic behaviours because there is not reflected tensile pulse recorded in the profiles and the time interval between the start of free surface motion and the moment of this reloading signal is less than the elastic wave reverberation time in the sample. And alumina does not behave plasticity in macroscope as typical brittle material, so this inelastic behaviour does not characterized plasticity though the free surface velocity profile has twowave structure. The additional weak compression wave is associated with a 
reflection from a layer of material which has dynamic impedance lower than that of the intact alumina, and this material layer bordering the interface does not pass tensile stresses. So we conclude that the shock-compressed alumina is comminuted behind this interface. This phenomenon is akin to the failure wave which has been observed to occur in glasses under shock compression.

On the assumption that the moving speed of failed layer boundary is the failure wave velocity $C_{F}$, a simple evaluating equation for $C_{F}$ has been derived as the following (see fig. 3, which shows diagram of elastic wave and failure wave propagating). The thickness of the failed layer $h_{f}$ is determined from the measured time interval of $t_{s}$ through the equation

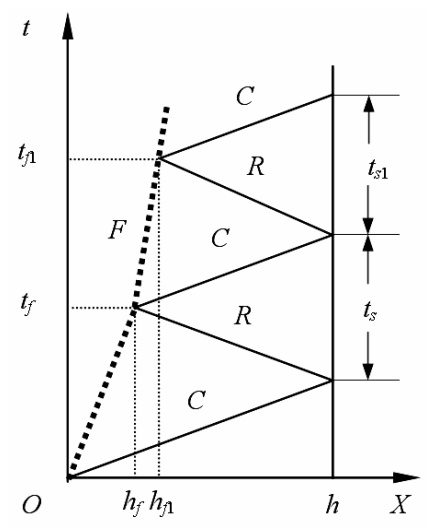

Figure 3: $\quad$ Propagation of $\boldsymbol{C}$ ompression, $\boldsymbol{R}$ arefaction and $\boldsymbol{F}$ ailure waves.

$$
h_{f}=h-\frac{1}{2} C_{P} t_{s}
$$

where $h$ is the sample thickness and $C_{P}$ is the longitudinal wave speed in alumina specimen. Then the failure wave velocity $C_{F}$ can be estimated by

$$
C_{F}=\frac{h_{f}}{h / C_{P}+t_{s} / 2}
$$

It implies that the failure wave has propagated at a velocity of $1.27 \mathrm{~km} / \mathrm{s}$ in shot 405 and $1.46 \mathrm{~km} / \mathrm{s}$ in shot 425 on average before the moment $t_{f}$. The free surface velocity history from VISAR measurements has shown that the failure front propagates at a speed much lower than longitudinal stress wave velocity, depending on the peak shock stress.

The free surface velocity profile from shot 425 is analyzed further in expanded region and there is another smaller recompression signal observed following the first (see fig. 4, which shows second smaller recompression indicated by a narrow). This can be explained if the reflected rarefaction wave from rear surface is reflected again on the failure layer and then reflected on rear surface where a weak jump of velocity is produced at the same time. During the 
time interval $t_{s 1}$ of two recompression signals, the distance of failure layer expanded can be determined through

$$
\Delta h_{f}=h_{f 1}-h_{f}=h-\frac{1}{2} C_{P} t_{s 1}-h_{f}
$$

Then the average velocity $C_{F 1}$ of failure wave propagating from the moment $t_{f}$ to $t_{f 1}$ can be estimated from the measured time interval of $t_{s 1}$ by

$$
C_{F 1}=\frac{\Delta h_{f}}{\left(t_{s}-t_{s 1}\right) / 2}
$$

This implies that the failure wave has propagated at an average velocity of $210 \mathrm{~m} / \mathrm{s}$ in shot 425 following unloading by the reflected rarefaction wave. This unloading slows down and even eventually arrests the failure procedure in material and results in great lowness in the failure wave propagating.

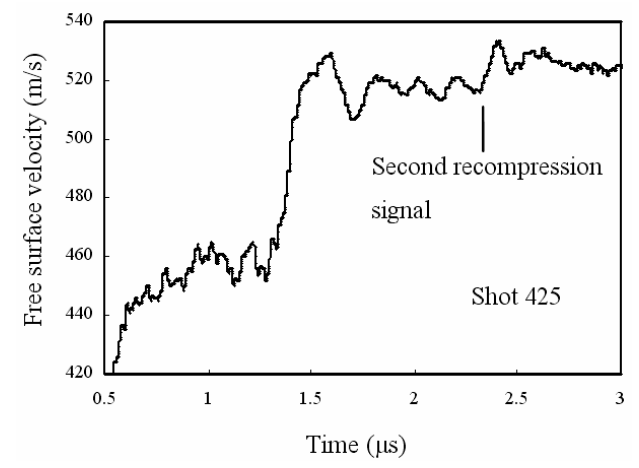

Figure 4: $\quad$ Expanded region of free surface velocity profile of shot 425.

\section{SEM for samples}

To explain the failure process of shock-compressed polycrystalline ceramics in mesoscope, initial and soft-recovered samples were scanned by S530 scanning electron microscope. Each fragment was cut in the centre along a plane parallel to impact surface with $0.2 \mathrm{~mm}$ distance to impact surface. Fig. 5(A) shows the micro-structures of initial $92.93 \mathrm{wt} \%$ alumina. Grains and intergranular pores distribute randomly with diameters $1-15 \mu \mathrm{m}$. Intergranular glassy phase is distinct in compact area. And initial porosity is $5.68 \%$ determined by metallurgical analysis software. Pores and glasses weaken mechanical capabilities and these heterogeneous meso-structures result in high singularity in stress distribution. Fig. 5(B) shows intergranular microcracks in recovered sample after 5.76GPa loading and Fig. 5(C) shows transgranular microcracks in recovered sample after 8.65GPa loading. Microcracking transmits from intergranular to transgranular with increasing impact compression. Alumina grains begin to fragment with transgranular microcracks and original pores begin to collapse. And discontinuous microcracks induce dilation after unloading. 


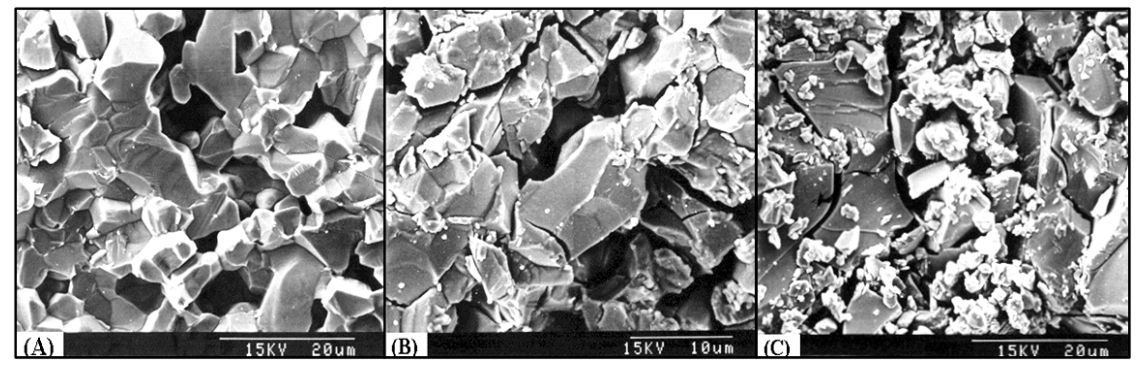

Figure 5: $\quad$ SEM micrographs of (A) initial and recovered alumina samples under (B) 5.76 GPa and (C) $8.65 \mathrm{GPa}$ shock loading.

The polycrystalline ceramics are heterogeneous in mesoscope. There are many pores, microcracks and other defaults inducing high singularity in stress distribution. Once the local stress exceeds the threshold, the original microcracks will grow up along the pores and crystal boundaries and new microcracks will nucleate in ceramics under shock loading. The original and nucleated microcracks grow up and expand, then excite the neighbour microcracks nucleation and expansion. So the failure wave appears and propagates from impact surface to interior of specimen, and it propagates at higher velocity under stronger shock loading. In essence, the failure wave is characterized by moving damage or fracture zone of material which presented by microcracking system in mesoscope, and it is also called after fracture wave by Resnyansky et al [12].

\section{Summary}

Ceramics are extensively applied to national defence engineering and military science as effective armour defence with their excellent physical and mechanical capabilities, especially higher dynamic elastic threshold and acoustic velocity than metals. We performed plate impact experiments of $92.93 \mathrm{wt} \%$ aluminas with 100-mm-diameter compressed-gas gun and the free surface velocities were traced by VISAR. There is a reloading signal observed in free surface velocity which indicates the failure wave propagation behind the elastic precursor. The failure wave propagates at a speed much lower than longitudinal stress wave velocity, depending on the peak shock stress. And the failed layer has much lower dynamic impedance than that of the intact material. The unloading by the reflected rarefaction wave slows down and even eventually arrests the failure front propagating in alumina. SEM analysis of intact samples shows heterogeneous meso-structures, and SEM analysis of soft-recovered samples shows transit of intergranular microcracks to transgranular microcracks with increasing shock loading. The failure wave is a continuous fracture or damage front which may be associated with nucleation and expansion of microcracks from impact surface to interior during the propagation of shock waves. 


\section{References}

[1] Bless, S.J., Brar, N.S. \& Rosenberg Z., Failure of Ceramic and Glass Rods under Dynamic Compression. Shock Compression of Condensed Matter1989, eds. S.C. Schmidt, APS: New Mexico, USA, pp. 939-942, 1990.

[2] Rasorenov, S.V., Kanel, G.I., Fortov, V.E., \& Abasehov, M.M., The Fracture of Glass under High-pressure Impulsive Loading. High Pressure Research, 6, pp. 225-232, 1991.

[3] Rosenberg, Z., Bourne, N.K., \& Millett, J., Direct Measurements of Strain in Shock-loaded Glass Specimens. Journal of Applied Physics, 79, pp. 3971-3974, 1996.

[4] Bourne, N.K., Millett, J., \& Rosenberg, Z., On the Origin of Failure Waves in Glass. Journal of Applied Physics, 81, pp. 6670-6674, 1997.

[5] Millett, J., Bourne, N.K., \& Rosenberg, Z., Measurements of Strain in a Shock Loaded, High-density Glass. Shock Compression of Condensed Matter-1999, eds. M.D. Furnish, AIP: Utah, USA, 505, pp. 607-610, 2000.

[6] Cazamias, J.U., Fiske, P.S., \& Bless, S.J., Sound Speeds of Post-failure Wave Glass. Fundamental Issues and Applications of Shock-Wave and High-Strain-Rate Phenomena, EXPLOMET 2000, eds. K.P. Staudhammer, New Mexico, USA, pp. 173-179, 2000.

[7] Bourne, N.K., Millett, J., Pickup, I., Delayed failure in shocked silicon carbide. Journal of Applied Physics, 81(9), pp. 6019-6023, 1997.

[8] Zhang, Q.M., Huang, F.L., \& Han, L.M., Failure Wave Motion of 3D$\mathrm{C} / \mathrm{SiC}$ Composites Subjected to Shock Compression. Chinese Science Bulletin, 45, pp. 408-411, 2000.

[9] Grote, D.L., Park, S.W., \& Zhou, M., Experimental Characterization of the Dynamic Failure Behavior of Mortar under Impact Loading. Journal of Applied Physics, 89, pp.2115-2123, 2001.

[10] Kanel G.I., Bogatch A.A., Razorenov S.V., \& Zhen Chen, Transformation of shock compression pulses in glass due to the failure wave phenomena. Journal of Applied Physics, 92(9), pp. 5045-5052, 2002.

[11] Zhao J.H., Sun C.W., Zhao F., Duan Z.P., et al, Velocity overshoot of rear free-surfaces of glass under impact. Explosion and Shock Waves, 22(1), pp. 72-78, 2002. (in Chinese)

[12] Resnyansky, A.D., Romensky, E.I., \& Bourne, N.K., Constitutive Modeling of Fracture Waves. Journal of Applied Physics, 93, pp. 1537$1545,2003$. 